\title{
Desenvolvimento de produtos tradicionais artesanais e destinos turísticos regionais no contexto da indústria criativa ${ }^{1}$
}

Traditional craft product development and regional tourist destinations in the creative industry context

Desarrollo de productos tradicionales artesanales y destinos turísticos regionales en contexto de la industria creativa http://dx.doi.org/10.18472/cvt.17n3.2017.1205

Gustavo Melo-Silva 〈 gustavomelosilva@ufsj.edu.br > Universidade Federal de São João del-Rei (UFSJ), São João del-Rei, MG, Brasil

Magnus Luiz Emmendoerfer 〈magnus@ufv.br >

Universidade Federal de Viçosa (UFV), Viçosa, MG, Brasil

Joaquim Filipe Esteves Ferraz de Araújo < jfilipe@eeg.uminho.pt >

Universidade do Minho, Portugal

1 Trabalho resultante de parceria interinstitucional de pesquisa científica com fomento do Conselho Nacional de Desenvolvimento Científico e Tecnológico (CNPq), processo 471136/2014-0, e da Fundação de Amparo à Pesquisa do Estado de Minas Gerais (Fapemig), processo APQ-01870-15.

CRONOLOGIA DO PROCESSO EDITORIAL

Recebimento do artigo: 02-fev-2016

Aceite: 22 -jun-2017

FORMATO PARA CITAÇÃO DESTE ARTIGO

MELO-SILVA, G.; EMMENDOERFER, M. L.; ARAÚJO, J. F. E. F. de. Desenvolvimento de produtos tradicionais artesanais e destinos turísticos regionais no contexto da indústria criativa. Caderno Virtual de Turismo. Rio de Janeiro, v. 17, n. 3, p. 131-147, dez. 2017.

REALIZAÇÃO

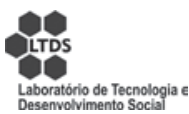

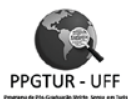

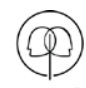

APOIO INSTITUCIONAL

EDIÇÃO

PATROCÍNIO

COPPE

UFR] 


\section{RESUMO}

As atividades econômicas artesanais compõem um Sistema Produtivo Tradicional (SPT) no contexto das Indústrias Criativas e de um destino turístico. Nesse sentido, o objetivo deste trabalho foi compreender a gestão de portfólio de produtos de SPTs de base artesanal têxtil e mineroartesanal, os quais estão conectados com destinos turísticos regionais. Estes SPTs lidam, por um lado, com a competição, gestão e produtos e, por outro lado, com uma realidade social de: tomada de decisão coletiva; necessidade de transparência; possibilidades de entendimentos entre interesses econômicos e sociais; e de emancipação dos moradores dos destinos analisados. Em cada SPT foi realizado um estudo multicaso, que compreendeu pesquisas e análises bibliográfica e documental. Os resultados mostram que a divisão do trabalho e a especialização são características do SPT contemporâneo e que essa configuração estrutural inibe a inovação no desenvolvimento de produtos para atender ao mercado turístico com suvenires.

Palavras-chave: Desenvolvimento Local. Turismo Cultural. Artesanato. Suvenires.

\section{ABSTRACT}

Craftsmanship is a Traditional Productive System (TPS) in the context of Creative Industries and an important component of a tourist destination. In this sense, the objective was to understand the portfolio management of craft textile and craft mining products based TPSs, which are connected with regional tourist destinations. On one hand, these TPSs deal with competition, management and products and, on the other hand, with a social reality: collective decision making; need for transparency; possibilities of understanding economic and social interests; and the emancipation of the residents of the analyzed destinations. In each TPS, a multicase study was conducted, which included research and bibliographical and documental analysis. The results show that the division of labor and specialization is a feature of the TPS contemporary and that this structural configuration inhibits innovation in the development of products to meet touristic market with souvenirs.

Keywords: Local development. Culture tourism. Handmade. Souvenirs.

\section{RESUMEN}

El trabajo artesanal es un sistema productivo tradicional (SPT) en el contexto de las industrias creativas y el componente importante de un destino turístico. En este sentido, el objetivo fue entender la gestión de la cartera de productos de SPTs de base artesanal textil y de la minería artesanal, que se conectan con destinos turísticos regionales. Estos SPTs manejan por un lado, con la competición, la gestión y los productos, por otro lado, con una realidad social de: toma de decisiones colectiva; la necesidad de transparencia; posibilidades de entendimientos entre los intereses económicos y sociales; y la emancipación de los residentes de los destinos analizados. En cada SPT fue hecho un estudio multi-caso con investigaciones y análisis bibliográfico y documental. Los resultados muestran que la división del trabajo y la especialización son características del SPT contemporáneo y que esta configuración estructural inhibe la innovación del desarrollo de productos para atender el mercado turístico con recuerdos.

Palavras clave: Desarrollo local. Turismo cultural. Artesanía. Recuerdos. 


\section{INTRODUÇÃO}

A realização do potencial existente do mercado de bens simbólico-culturais e das indústrias criativas tem revelado a necessidade de parcerias entre o Estado, a iniciativa privada e organizações da sociedade civil. Tal necessidade é visível no contexto das comunidades que produzem produtos tradicionais em pedra-sabão e têxteis, que vivenciam os benefícios e os problemas das fronteiras entre as dimensões comerciais, artísticas e tradicionais na condução dos seus negócios com enfoque em atividades econômicas do setor turístico. Assim, um dos pressupostos deste trabalho é que há uma relação dialética entre produtos contemplados no contexto das indústrias criativas como o artesanato (HARTLEY, 2005; SILVA; EMMENDOERFER; NEVES, 2009) e que estão inseridos em destinos turísticos como suvenires associados a eles.

A gestão de portfólio de produtos ganha importância, entre os limites tênues dos interesses econômicos e culturais, como um programa organizacional complexo composto por inúmeras variáveis que interferem diretamente nos investimentos de recursos em pesquisa e desenvolvimento de produtos como suvenires para atender à demanda gerada pelo turismo (LITTRELL; ANDERSON; BROWN, 1993; HITCHCOCK; TEAGUE, 2000).

A demanda turística movimenta o mercado de suvenires como os de base artesanal com origem na tradição do local ou da região. A demanda por suvenires ou produtos provenientes de Sistemas Produtivos Tradicionais (SPTs) articula diversos atores socioeconômicos em mercados municipais que fomentam o desenvolvimento local de vários países, inclusive do Brasil. Nesse sentido, o processo de construção dos mercados a partir de SPTs pode ser caracterizado como uma relação fruto da interação da sociedade civil organizada e imersa, conforme Granovetter (2002), em laços fortes e fracos, que conformam as relações de confiança nos territórios, e que podem ser intensificados pela demanda por suvenires em destinos turísticos.

Com base nessa hipótese, argumenta-se que a realidade socioeconômica de um SPT pode envolver a gestão do espaço público construído por trabalhadores, artistas, famílias, comerciantes, empresários e governos de distintos períodos e níveis da administração pública. Somado a isso, os produtos de SPTs intermediam a troca de trabalho tradicional nos territórios por renda decorrente da comercialização via estabelecimentos formalmente instalados no mercado turístico. Esses produtos são desenvolvidos em domicílios e estabelecimentos comerciais com contribuições públicas e privadas. O desenvolvimento dos produtos tradicionais faz parte de um SPT e contribui com a gestão de destinos turísticos com suvenires. Portanto, tendo por um lado os produtos de SPT artesanais como fenômenos organizacionais e, por outro lado, as possibilidades e limites do desenvolvimento de produtos como suvenires em mercados turísticos, tem-se a questão que norteou este artigo: Como é a gestão de portfólio de produtos tradicionais artesanais para atender às demandas em destinos turísticos?

Portanto, o objetivo deste estudo é compreender a gestão de portfólio de produtos de Sistemas Produtivos Tradicionais de base artesanal têxtil e mineroartesanal. A importância deste estudo reside na compreensão de dinâmicas que contribuem para a qualidade e a competitividade dos destinos turísticos, bem como revela as relações socioeconômicas produtivas de trabalho e renda que a atividade turística movimenta em níveis local e regional no contexto contemporâneo das indústrias criativas. Tal análise inova ao deslocar o centro das atenções dos estudos sobre suvenires e destinos turísticos (HORODYSKI; MANOSSO; GÂNDARA, 2012) ao abordar a gestão de portfólio, inclusive o processo de inovação, de 
produtos como suvenires produzidos a partir de mercados tradicionais artesanais locais para atender às demandas turísticas regionais.

\section{Mercados, organizações e desenvolvimento de produtos artesanais como suvenires}

Primeiramente, a presente revisão de literatura trata sucessivamente de conceitos de mercado em que a gestão do desenvolvimento de produto deve ser considerada. Ressalta-se que houve uma tentativa de aproximar a literatura especializada disponível, que se concentra em médias e grandes empresas, com o contexto das organizações tradicionais em virtude da incipiente produção científica contemporânea sobre o tema.

Nesse sentido, um produto é "qualquer coisa que possa ser trocada entre indivíduos e organizações" (ROCHA; CHRISTENSEN, 1999, p. 86-88). Os produtos descritos neste trabalho foram autodefinidos por seus produtores como artesanais. Para Souza (1993, p. 35), o valor do artesanato reside na "capacidade imaginativa e criatividade do artesão ao desenvolver sua peça que constitui a expressão de suas origens, enquanto o desejo do mercado consumidor é adquirir uma peça artesanal cuja qualidade e expressão cultural as diferenciam do produto industrial fabricado em série". Ou seja, a troca que ocorre na compra de um produto artesanal envolve também a transmissão, do produtor para o comprador, de elementos criativos, relacionados às origens e à cultura do artesão.

Somado a isso, o produto artesanal como um suvenir representa uma lembrança materializada de um objeto que evoca memórias e recordações significativas de experiências em um determinado lugar, em uma relação entre o passado e o presente (MORGAN; PRITCHARD, 2005), por parte do viajante enquanto consumidor de produtos turísticos, cuja interpretação e análise é plural e diversificada pelos pesquisadores sobre o assunto (HORODYSKI; MANOSSO; GÂNDARA, 2012).

Para atenderem às demandas do mercado turístico, as organizações cada vez mais desenvolvem seus negócios e produtos com a orientação para o mercado. Essa orientação tem origem na década de 1990 por meio de investigações e reflexões sobre as relações entre o conceito de marketing e o desempenho das organizações. Essas investigações e reflexões direcionaram o marketing para um foco sobre os consumidores e os competidores, estimulando a coordenação interfuncional entre departamentos empresariais (NARVER; SLATER, 1990; HUNT; LAMBE, 2000).

As organizações podem buscar a diferenciação de seus produtos, isto é, "desenvolver um conjunto de diferenças significativas para distinguir a oferta da empresa da oferta da concorrência” (KOTLER; KELLER, 2006, p. 309). Por diferenças significativas, entende-se diferenças que sejam percebidas como vantagens pelos clientes. Para que isso possa ser feito, é preciso que a oferta seja concebida a partir das necessidades dos consumidores. Inversamente, segundo Kotler e Keller (2006), a sequência de criação e entrega de valor tem início na seleção do valor, que se baseia na segmentação de clientes, foco no mercado e posicionamento da oferta (do destino turístico), prossegue com o processo de fornecimento do valor e, finalmente, com a comunicação do valor (imagem do destino). Contudo, cabe ressaltar que a oferta e o consumo de suvenires reforçam a orientação para o mercado turístico e possuem um representativo poder simbólico (BOURDIEU, 2011) associado ao destino visitado (FREIRE-MEDEIROS; CASTRO, 2007), por estar ligado a um valor hedônico e pouco utilitário (GORDON, 1986). 
A perspectiva de orientação para o mercado considera os concorrentes potenciais. A organização atua na prevenção dos riscos associados a mudanças tecnológicas e em consumidores potenciais, de modo a evitar um foco exclusivo nas necessidades e desejos expressos pelos consumidores atuais (HUNT; LAMBE, 2000). Como alerta Brown (1997), a ênfase absoluta na satisfação das necessidades dos clientes pode reprimir a criatividade e as inovações, consideradas essenciais em indústrias criativas relacionadas com o turismo (EMMENDOERFER; ASHTON, 2014), pois os consumidores não são, na maioria dos casos, capazes de identificar suas necessidades latentes.

A inovação e a criação de novos produtos são fatores essenciais para a competitividade das organizações econômicas (KOTLER; TRIAS DE BES, 2004). Para Griffin e Page (1996), as organizações econômicas têm sucesso em inovação e desenvolvimento de produtos com: (1) estratégias de produto e (2) inovações estratégicas de negócios. Eles distinguem as seguintes categorias de inovação de produto: (1) novos para o mundo; (2) novos para a organização; (3) melhoria de produtos; (4) extensões de linha; e (5) reposicionamento de produtos. Kotler e Trias de Bes (2004) alertam que a maioria das práticas de inovação não cria novas categorias ou novos mercados, pois elas ocorrem dentro da categoria em que os produtos concorrem. No entanto, conforme Kotler e Trias De Bes (2004, p. 79), "a criação de um novo mercado ou categoria é a maneira mais eficiente de concorrer em mercados maduros”.

O desempenho das organizações em matéria de desenvolvimento de novos produtos depende, por sua vez, dos modelos e das práticas de gestão adotados pelas organizações (GAVIRA et al., 2007), que pode compreender duas dimensões: o planejamento e a execução do ciclo de desenvolvimento do produto. $\mathrm{O}$ ciclo de desenvolvimento do produto designa as etapas sucessivas do processo, começando com a geração de ideias de produtos até o lançamento destes. Entre a ideia e o lançamento existem a pesquisa de mercado, a seleção de conceito, o projeto de produto e o processo de pré-produção.

Para obter resultados compatíveis com os ambientes empresariais, cada vez mais competitivos, são necessários esforços, competências e habilidades complexas, organizadas e integradas. De acordo com Clark e Wheelwright (1993), a estrutura organizacional de grupos de desenvolvimento de produtos é composta por equipes multifuncionais, ágeis, com autonomia decisória e técnica. Essas formas de estrutura organizacional são formalizadas a partir de aspectos, como autoridade, responsabilidade, competência, habilidades, relações interfuncionais e liderança. O processo de desenvolvimento de produtos está estreitamente relacionado à estrutura organizacional. $\mathrm{O}$ uso de estruturas organizacionais adequadas, para cada produto em desenvolvimento, potencializa o êxito do produto orientado para o mercado. Além dos produtos, o processo também é influenciado pela gestão de portfólio dos produtos.

A gestão de portfólio é um ponto vital, já que o desempenho bem-sucedido de um novo produto é fundamental para o sucesso da organização e não é diferente com produtos de base artesanal. O novo produto pode ser entendido metaforicamente como uma "manifestação" da estratégia do negócio e pode indicar a eficiência na alocação de recursos. O estudo de Cooper, Edgett e Kleinschmidt (1997a) mostrou que as organizações admitem que não existe uma resposta única e correta para o desenvolvimento de produtos.

Segundo Cooper, Edgett e Kleinschmidt (1997b), o processo de desenvolvimento de produtos leva as organizações ao desenvolvimento de programas de gestão de portfólio, a qual é fomentada pelo processo de desenvolvimento de produtos, que identifica e pontua questões como: (1) insatisfação com a qualidade atual dos projetos; (2) projetos de produtos e mercados em estágios e prioridades com diferentes custos e importâncias estratégicas para a organização; (3) decisões baseadas em critérios objetivos que representem 
tanto valores dos consumidores como também institucionais do mercado; (4) diversidade de projetos para recursos limitados, o que leva as organizações a uma maior busca de eficiência na alocação de recursos; e (5) existência de projetos de produtos que podem demorar anos para chegarem ao mercado com períodos de inatividade de desenvolvimento, mudança de nome, perda de foco e prioridade.

\section{PERCURSO METODOLÓGICO}

A estratégia de pesquisa foi de estudo multicaso (MORRA; FRIEDLANDER, 1999), especificamente da gestão de portfólio de produtos provenientes de SPTs que atendem a destinos turísticos regionais. Os produtos dos destinos turísticos abordados para levantar respostas para o problema de pesquisa traçado neste artigo foram delimitados por produtos e por espaço no contexto brasileiro. Em um caso, no entorno das cidades turísticas de São João del-Rei e Tiradentes, que compõem o circuito turístico "Trilha dos Inconfidentes", foi analisado o produto do mercado têxtil tradicional do município de Resende Costa. E em outro caso, em municípios que compõem o circuito turístico do "Ouro", foi analisado o produto em pedra-sabão do mercado mineroartesanal dos municípos de Catas Altas da Noruega, Mariana e Ouro Preto. Ressalta-se que o termo "circuito turístico" refere-se aos roteiros regionalizados relacionados à política pública estadual de turismo criada em 2003 e atualmente vigente no estado de Minas Gerais, Brasil (EMMENDOERFER; SILVA; EMMENDOERFER; FONSECA, 2007; SOARES; EMMENDOERFER; MONTEIRO, 2013).

O circuito Trilha dos Inconfidentes encontra-se no Campo das Vertentes, mesorregião do estado de Minas Gerais. A partir da década de 1980, a base socioeconômica dessa região esteve centrada no turismo relacionado com o patrimônio histórico e cultural regional, decorrente da exploração do ouro nesse território no século XVIII. O turismo incentiva a produção tradicional nos destinos turísticos de São João del-Rei, de Tiradentes e em cidades vizinhas, com a produção de peças de estanho em São João delRei, em Resende Costa com o tear manual e em Prados com esculturas de madeira (SILVA; ALMEIDA; FERREIRA, 2014).

O circuito do Ouro está localizado na região central do estado de Minas Gerais e tem como principais marcos históricos e turísticos as cidades de Mariana e Ouro Preto. Essa região turística possui um importante patrimônio histórico material e imaterial, decorrente da colonização portuguesa que, desde 1709, constituiu a Capitania de Minas Gerais, cuja vila principal foi Vila Rica de Nossa Senhora do Pilar do Ouro Preto, atual município de Ouro Preto (MG), que foi considerado, pela Organização das Nações Unidas para a Educação, a Ciência e a Cultura (Unesco), como Patrimônio Cultural da Humanidade. Mariana foi a primeira vila, capital, bispado e cidade a ser projetada em Minas Gerais. Os produtos turísticos a serem analisados nesse território são os utensílios domésticos e peças de decoração em esteatita ou pedra-sabão. Os municípios de Catas Altas da Noruega, Mariana e Ouro Preto abastecem o varejo e atacado de souvenir e de decoração dos estabelecimentos comerciais dos municípios de Mariana e Ouro Preto (SILVA; TANNUS; MOREIRA, 2006).

Atualmente podemos considerar, inclusive como critérios de seleção dos casos em análise, que os SPTs têxtil e mineroartesanal desses destinos turísticos regionais possuem características de estágios evolutivos distintos. A forma híbrida desse sistema de produção, que aglutina em sua constituição e operacionalização atores familiares e empresariais, aumenta a complexidade da gestão do desenvolvimento de seus produtos. 
As organizações, para se tornarem competitivas no mercado turístico desses circuitos, estimularam a relação de grupos sociais locais (famílias, amigos, etc.) com conhecimento tradicional com o mercado turístico.

Para a compreensão da inserção do produto têxtil no mercado de Resende Costa, foram analisados os dados de Silva (2010), que visitou 2.655 domicílios no perímetro urbano da sede do município, dos quais 796 foram autodefinidos pelos entrevistados como um domicílio em que existia alguma atividade produtiva da tecelagem tradicional. Levando em consideração as recusas e os questionários inválidos, obteve-se uma amostra final de 664 questionários válidos. Para o questionário comercial, foram visitados 76 estabelecimentos, nos quais 69 proprietários aceitaram responder ao questionário. Os dados dos produtores e comerciantes de Resende Costa foram: perfil socioeconômico do respondente e da unidade de observação, caracterização das atividades produtiva e comercial, organização do trabalho, características e consumo de insumos e equipamentos, perfil da produção e percepções dos entrevistados sobre o mercado.

Para a compreensão da inserção do produto mineroartesanal no mercado da região de Catas Altas da Noruega, Mariana e Ouro Preto, foram analisados os dados disponíveis na Fundação Centro Tecnológico de Minas Gerais (2006) e Silva, Tannús e Moreira (2006). Os dados desse sistema produtivo tradicional tiveram como fonte o relatório da Fundação Centro Tecnológico de Minas Gerais (2006). A amostra dessa pesquisa foi não probabilística e intencional. As organizações dos sistemas produtivos tradicionais desses municípios eram informais e estavam localizadas nos domicílios de seus produtores. Foram identificadas 166 unidades produtivas artesanais, que estão distribuídas em três municípios - Catas Altas da Noruega, Mariana e Ouro Preto - e, respectivamente nestes, em nove comunidades. No município de Ouro Preto, as unidades produtivas estavam distribuídas em dois distritos e em três comunidades rurais. No município de Mariana, as unidades produtivas estavam distribuídas em um distrito e em duas comunidades rurais. Das 166 unidades visitadas, 140 foram pesquisadas, sendo que a distribuição das unidades produtivas mineroartesanais por municípios foi a seguinte: $62,04 \%$ em Ouro Preto; $34,34 \%$ em Mariana; e 3,62\% em Catas Altas da Noruega. Destas, em 140 oficinas foi aplicado um questionário para o proprietário ou responsável e 15 proprietários foram entrevistados por meio de roteiros semiestruturados (FUNDAÇÃO CENTRO TECNOLÓGICO DE MINAS GERAIS, 2006; SILVA; TANNÚS; MOREIRA, 2006).

Com base nas fontes de dados bibliográficos e documentais mencionados, procedeu-se à organização e cotejamento dos dados coletados que permitiram, com foco no objetivo desta pesquisa e à luz da revisão de literatura apresentada no tópico anterior, apresentar e discutir os resultados expostos nos tópicos subsequentes.

\section{Organizações para mercados de produtos turísticos: Análise dos Sistemas Produtivos Tradicionais têxtil e mineroartesanal em Minas Gerais, Brasil}

Nos circuitos turísticos do Ouro e Trilha dos Inconfidentes analisados, ambos em Minas Gerais Brasil, existem Sistemas Produtivos Tradicionais (SPTs) têxtil e mineroartesanal. No comércio local, esses produtos são denominados e comercializados como artesanato, tratado como suvenir nas cidades turísticas nesses circuitos.

O artesanato está associado à existência de hábitos e conhecimentos transmitidos de uma geração à outra; ele se insere em uma tradição cultural (MAZZA; IPIRANGA; FREITAS, 2006; SOARES; FISHER, 2010). Esse produto possui um processo criativo em que se pressupõe que haja liberdade de criação do 
artesão, que deve, em princípio, ter domínio do processo de fabricação, desde a concepção do produto até a conclusão de sua produção (SOARES; FISHER, 2010).

\section{0 produto têxtil de Resende Costa $(\mathbf{M g})$}

As primeiras famílias que fundaram a cidade de Resende Costa (MG), em 1749, transmitiram para as gerações seguintes a arte de fiar e tecer artesanalmente. A tecelagem não tinha, inicialmente, fins comerciais. Tecia-se para confeccionar roupas e adereços para festas e cerimônias religiosas. A tradição se manteve ao longo de mais de dois séculos. Na década de 1980, a produção e comercialização de utensílios domésticos e peças decorativas têxteis foram impulsionadas pelo turismo das cidades de São João delRei e Tiradentes. Silva (2010) identificou, no final da década de 2010, 1.072 trabalhadores domiciliares nas ocupações de tecer, enrolar novelos de retalho, picar retalho e acabar peças. A especialização de mercado não se restringiu à produção domiciliar. $\mathrm{O}$ elo comercial da tecelagem tradicional também se especializou nas funções de produzir, comercializar peças e fornecer insumos. As 191 pessoas ocupadas nos estabelecimentos comerciais se especializaram como vendedores e como gestores (SILVA, 2010).

Conforme Silva (2010), os domicílios produtores em 2009 eram, em sua maioria, prestadores de serviços, isto é, comercializavam o serviço de tecer $(42,1 \%)$, de picar retalho $(6,9 \%)$ e enrolar o novelo de retalho (4,6\%). Os domicílios produtores exerciam a função de produzir e vender peças da tecelagem (28,9\%), comercializar novelos de retalho $(5,8 \%)$ e vender retalho picado $(4,4 \%)$. O sistema produtivo tradicional têxtil foi, de acordo com Silva (2010), organizado burocraticamente entre domicílio produtor e estabelecimentos comerciais, principalmente, a partir do final do século XX. Até o final da década de 1960, os produtos oriundos do município eram comercializados majoritariamente por vendedores ambulantes. A partir do final da década de 1980, surgiram as primeiras lojas implantadas na cidade. Esse movimento se ampliou na década de 1990, com o desenvolvimento do turismo em Tiradentes (SANTOS; SILVA, 1997).

Para Silva (2010), os proprietários dos estabelecimentos comerciais especializados em produtos locais assumiram a liderança do processo de fabricação, comprando dos domicílios produtos acabados e fornecendo insumos para sua produção (novelos de retalhos e produtos inacabados). Os empreendedores comerciantes estavam em contato direto com os compradores (turistas e lojistas de outras cidades) e, consequentemente, com as demandas do mercado local. Os comerciantes exercem, hoje, o controle social da produção domiciliar para alcançar o diferencial competitivo de qualidade dos produtos. O perfil da demanda dos compradores do sistema produtivo tradicional em 2009 era, conforme Silva (2010), de 80\% de lojistas. No entanto, o crescimento do turismo na região tornou mais presente o consumidor final nos estabelecimentos comerciais. Em 1997, conforme Santos, Silva e Moretti (1998), eles representavam 2\% dos compradores nos estabelecimentos comerciais. Já em 2009 eram, conforme Silva (2010), de 20\%. Dado o crescimento do turismo local, existe a tendência do aumento da frequência do comprador turista para a comercialização local nos próximos anos.

\section{O produto mineroartesanal de Catas Altas da Noruega, Mariana e Ouro Preto}

A pedra-sabão é um mineral utilizado em obras de arte e acabamentos da construção civil. Esse material é insumo fundamental para um produto tradicional da região dos municípios mineiros de Catas Altas da Noruega, Mariana e Ouro Preto. Os objetos de decoração, panelas e utensílios domésticos abastecem o varejo de suvenir e de decoração, principalmente dos municípios de Mariana e Ouro Preto. 
O principal produto das oficinas mineroartesanais identificado no estudo da Fundação Centro Tecnológico de Minas Gerais foi a panela de pedra que era produzida por 30\% das oficinas entrevistadas. Nesse sistema, observa-se, também, o fenômeno da especialização. Porém, esta é organizada, em um primeiro nível, por produto. As oficinas localizadas em Mariana são especialistas na produção de panelas; as dos municípios de Ouro Preto e de Catas Altas da Noruega concentram a fabricação de peças e utensílios de decoração.

O município de Mariana reúne as oficinas responsáveis pela produção do produto principal, especificamene o distrito de Cachoeira do Brumado, responsável por 52,4\% da produção de panelas. No distrito de Santa Rita de Ouro Preto existe uma concentração de 40,38\% de oficinas especializadas em esculturas, tabuleiros e peças de jogo de xadrez. No distrito de Cachoeira do Campo de Ouro Preto, 30,77\% das oficinas são especializadas em esculturas, fontes e cascatas (FUNDAÇÃO CENTRO TECNOLÓGICO DE MINAS GERAIS, 2006).

Os 370 trabalhadores pesquisados se distribuem também em ocupações diversas do sistema produtivo, sendo que a mais representativa foi a de artesão, que correspondeu a 53,24\% dos trabalhadores. Entretanto, a especialização do trabalho não se limita às oficinas, já que 9,19\% de trabalhadores se especializaram na função de escultor, 7,03\% de operador de serra de poli-corte, $10 \%$ de torneiro e 7,57\% de acabador de peças (FUNDAÇÃO CENTRO TECNOLÓGICO DE MINAS GERAIS, 2006).

\section{Sistemas Produtivos Tradicionais Orientados para Produtos Artesanais em Destinos Turísticos Regionais: Diferenciais Competitivos e Inovação}

Em Resende Costa, as peças mais produzidas são o tapetinho, tapete, jogo americano e guardanapos. Chama atenção nos dados a produção unitária mensal, em 2009, de 131.088 tapetinhos, que, comparada com a que foi registrada por Santos, Silva e Moretti (1998) em 1996, indica que a produção dessa peça aumentou aproximadamente $240 \%$ no período analisado. Entretanto, outras peças, como tapete, jogo americano e guardanapos, são produtos com volume de produção considerável. Em 2009, os domicílios produziam aproximadamente 210.000 peças por mês. É importante observar aqui que os tapetinhos, com dimensões aproximadas de $45 \mathrm{~cm}$ de largura por 75 de comprimento e confeccionados a partir de novelos de retalhos, são produtos de baixo valor unitário, com preços de venda, nas lojas, que variam entre $\mathrm{R} \$ 2,00$ e $\mathrm{R} \$ 3,00$ (SILVA, 2010).

No sistema de produção mineroartesanal da região de Ouro Preto e Mariana, além das panelas, os produtos que se destacam no portfólio das oficinais são o tabuleiro e peças de xadrez, que estavam presentes em $11,43 \%$ das oficinas, as esculturas em $10,71 \%$, as fontes e cascatas em $10 \%$ e as pequenas esculturas de animais, ou como são denominadas localmente, os bichinhos, em 6,43\%. Os produtos com maior produção são os bichinhos, bola, carro de boi, castiçal, fonte, cascata, forma de pizza, jogos, panela, peças ornamentais, porta-incenso, porta-joia, porta-retrato, relógio, jogo de resta-um, réchaud, imagens de santos, vasos e xadrez. As oficinas produziam aproximadamente 30.750 peças por mês. Em 2006, o preço médio de venda dos produtos mineroartesanais é de $R \$ 19,38$, entretanto, a variação é importante, indo de $\mathrm{R}$ \$,50 para uma tacinha a $\mathrm{R} \$ 500,00$ para um lavatório (FUNDAÇÃO CENTRO TECNOLÓGICO DE MINAS GERAIS, 2006).

Os dados dos dois estudos de caso apontam a existência de uma variedade considerável de produtos. Por exemplo, há 54 itens no portfólio do sistema produtivo tradicional mineroartesanal e aproximadamente 
100 itens no portfólio do sistema produtivo tradicional têxtil (FUNDAÇÃO CENTRO TECNOLÓGICO DE MINAS GERAIS, 2006; SILVA; TANNÚS; MOREIRA, 2006). Entretanto, no território dos produtos mineroartesanais, o mercado consumidor não valoriza a variedade de produtos. Esse fato foi relatado pelos entrevistados que se queixavam de frequentes perdas de recursos em peças que os consumidores não tiveram interesse de compra (FUNDAÇÃO CENTRO TECNOLÓGICO DE MINAS GERAIS, 2006).

A qualidade dos produtos comercializados no SPT têxtil de Resende Costa foi, para os proprietários dos estabelecimentos comerciais, o principal fator de competitividade e corresponde a $46,4 \%$ de suas opiniões, seguida pelo preço dos produtos (16\%), atendimento aos compradores (13\%) e originalidade dos produtos $(4,4 \%)$. Este último dado chama atenção e sinaliza a baixa preocupação dos produtores com a criação de produtos originais, capazes de diferenciá-los de seus concorrentes.

De fato, uma visita às diferentes lojas que se espalham ao longo da avenida principal da cidade evidencia que os produtos da tecelagem tradicional são similares entre si. Sem dúvida, o processo de divisão do trabalho dificulta a criação de peças originais, já que a maioria dos artesãos, com exceção de algumas mulheres tecelãs, que têm 60 anos ou mais, executa e domina somente parte das atividades envolvidas na fabricação do produto final, não tendo conhecimento do conjunto do processo, e, portanto, possibilidade de idealizar novos produtos. Somente $12 \%$ dos entrevistados nos domicílios produtores disseram criar novas peças. Por exemplo, sugestões de clientes para desenvolver peças com dimensões diferentes das atualmente existentes ou mesmo utilizar novos materiais para fabricar as peças já produzidas não são atendidas e nem mesmo testadas pelos trabalhadores nos domicílios produtores por estes desconhecerem o conjunto do processo produtivo e não conseguirem avaliar a viabilidade de novas demandas.

Portanto, a competição se dá, principalmente, por qualidade e preço. Mas a qualidade e os preços dos produtos são muito semelhantes de uma loja à outra, demonstrando a dificuldade de se construir uma vantagem competitiva sustentável a partir desses atributos. Para os lojistas entrevistados por Silva (2010), as menções ao atendimento aos compradores se referem à cordialidade no atendimento, bem como à oferta de formas de pagamento diferenciadas e garantia da entrega dos pedidos dentro dos prazos estabelecidos.

Para 38,04\% dos empreendedores do SPT mineroartesanal da região de Ouro Preto e Mariana, a qualidade é seu principal diferencial e, para $23,53 \%$, o preço é o que os diferencia no mercado. A marca não foi identificada por nenhum empreendedor local como um diferencial. $\mathrm{O}$ design e o cumprimento dos prazos de entrega da produção também foram considerados como diferenciais, representando respectivamente 14,9\% e 9,8\% das respostas (FUNDAÇÃO CENTRO TECNOLÓGICO DE MINAS GERAIS, 2006). Observa-se, assim, no sistema produtivo tradicional mineroartesanal a mesma tendência registrada no têxtil, ou seja, competir por preço e qualidade, mas é digna de nota a presença, nos diferenciais citados, do fator design, que remete à criatividade e à concepção de objetos a partir de sua idealização, e não de tarefas fragmentadas executadas sem visão ou acesso ao objeto em seu conjunto.

Conforme Silva (2010), para 34,8\% dos empreendedores comerciantes do SPT têxtil, o aspecto que deve ser melhorado na tecelagem tradicional é a criação de novas peças e serviços, seguida da remuneração $(8,7 \%)$, material utilizado $(8,7 \%)$, qualidade dos produtos $(8,7 \%)$ e cumprimento dos prazos de fornecimento $(5,8 \%)$. Vale ressaltar que se, por um lado, no domicílio produtor, os respondentes não tinham o interesse em desenvolver novas peças, como se viu anteriormente, por outro, para $34,8 \%$ dos proprietários dos estabelecimentos comerciais, essa é uma possibilidade de melhoria. Isso é percebido pelos comerciantes no contato com os clientes, que, ao frequentar as lojas, fazem sugestões e pedidos. 
Entretanto, o atual portfólio produzido pelo sistema produtivo tradicional desse município não vem atendendo integralmente a essa demanda. Tanto que, conforme Silva (2010), aproximadamente $45 \%$ dos produtos expostos nas prateleiras dos estabelecimentos comerciais locais não são originários da produção domiciliar local.

Para os empreendedores dos SPTs mineroartesanais, o desenvolvimento e a melhoria das embalagens dos produtos foram os aspectos destacados como prementes nos processos de melhoria do produto local, representando 33,52\% das respostas. Registra-se aqui que a pedra-sabão é um material frágil, sendo, portanto, exposto a quebras e danos em operações de transporte e manuseio. Outros aspectos também foram destacados, como o design $(14,84 \%)$ e o desenvolvimento de novos materiais a serem utilizados em conjunto com os produtos em pedra-sabão (12,08\%). Dos 140 proprietários de oficinas entrevistadas, 35 , ou seja, $25 \%$, não responderam a essa pergunta por não considerarem a melhoria dos produtos um aspecto relevante para a competitividade de suas oficinas (FUNDAÇÃO CENTRO TECNOLÓGICO DE MINAS GERAIS, 2006).

Chama atenção, nos resultados obtidos em ambos os casos, o fato de que os consumidores bem como suas necessidades e expectativas não foram mencionados. Isso sugere que, mesmo informalmente, não há um processo de captação desses elementos, indispensáveis (HUNT; LAMBE, 2000; KOTLER; KELLER, 2006) para uma abordagem de inovação e melhoria de produtos orientada para o mercado.

Finalmente, perguntou-se aos empreendedores do sistema produtivo tradicional mineroartesanal como eles desenvolviam produtos. A criação própria é a forma mais frequente, representando a origem de produtos em $28,27 \%$ das respostas dos entrevistados. A indicação ou solicitação de algum cliente e as encomendas representam respectivamente $21,56 \%$ e $25,44 \%$ das respostas (FUNDAÇÃO CENTRO TECNOLÓGICO DE MINAS GERAIS, 2006). É importante observar aqui que essas solicitações provêm de revendedores, que exercem, então, o papel de intermediários entre os produtores de peças artesanais e seus compradores finais que apropriam um valor tradicional nos produtos, ao consumi-los como suvenires.

\section{Limites e possibilidades da gestão de portfólio de produtos como suvenires em destinos turísticos regionais}

Os dados indicam que os sistemas produtivos estudados se caracterizam pela divisão e especialização do trabalho, assemelhando-se, portanto, a uma organização do trabalho manufatureira. Os trabalhadores eram especialistas, controlados por sua produtividade via remuneração variável. Essa rotina foi eficiente economicamente face às crescentes pressões de demanda do mercado consumidor. Entretanto, acarretou consequências não intencionais, especificamente, para a gestão da inovação e do portfólio de produtos.

O desenvolvimento de produtos dos SPTs têxteis e mineroartesanais analisados não revelou práticas e processos organizacionais de gestão de desenvolvimento de produtos, conforme Clark e Wheelwright (1993) e Cooper, Edgett e Kleinschmitt (1997a; 1997b), ao ponto de promover o planejamento de todo o ciclo de desenvolvimento de produtos. Segundo esses autores, isso seria importante para assegurar a qualidade e o atendimento dos desejos dos compradores turistas a partir das atividades produtivas internas à organização. Os resultados evidenciam que não existe uma definição de estratégia formal de desenvolvimento de novos produtos e muito menos processos administrativos que deem conta de selecionar projetos vencedores de novos produtos ou balancear o portfólio entre projetos. 
Os dados do SPT mineroartesanal indicam que o desenvolvimento de produtos é realizado por ações isoladas do proprietário $(28,27 \%)$, indicação de clientes $(21,56 \%)$ ou por encomendas de clientes $(25,44 \%)$. As encomendas são feitas por revendedores, que atuam como intermediários de mercadorias e dos desejos dos clientes finais, no caso os turistas nos destinos analisados. Outro fato, é que não existe um processo formal de pesquisa sobre esses desejos, ou seja, não se sabe formalmente os atributos que os turistas consumidores valorizam e os elementos em que se baseia sua percepção de valor. Infere-se que essa percepção de valor esteja associada à lembrança do local visitado experimentada durante o fazer turismo. Além disso, o desenvolvimento de produtos não considera, por exemplo, a escassez de matériaprima, que é uma consequência da especificidade do esteatito, que tem na sua extração um processo-chave que deveria ser considerado, conforme Cooper (1993), na análise da plataforma de produção das peças artesanais de pedra-sabão.

O que se observou nos dois casos estudados foi o desenvolvimento de sistemas produtivos em escala, onde as decisões relativas aos produtos foram influenciadas principalmente pelos empreendedores dos estabelecimentos comerciais, que informalmente estavam focados no atendimento do aumento da demanda dos destinos turísticos. Com isso, atendeu-se ao que o mercado pedia, em uma lógica que é, essencialmente, a da imitação, perdendo-se o caráter criativo do trabalho dos artesãos, que seria, potencialmente, seu principal diferencial.

Nos sistemas estudados, conforme a observação de Tavares e Pinto (2008), verificou-se que a orientação para o mercado pode estimular a imitação ou o lançamento de produtos marginalmente novos, limitando assim o surgimento de novas tecnologias e a competitividade das empresas. Não foram identificados, nas organizações para o mercado de produtos tradicionais pesquisadas, processos administrativos que atendam aos interesses privados e sociais via o desenvolvimento de novos produtos (KOTLER; TRIAS DE BES, 2004), que proporcionem inovações (GRIFFIN; PAGE, 1996) para atendimento de necessidades de consumo e de competitividade nos destinos turísticos.

Desperta preocupação o fato, claramente evidenciado nos dois casos estudados, da concorrência se basear, na óptica dos produtores, essencialmente em qualidade e preço. Isso parece ser, porém, a consequência lógica de um sistema que se baseia na imitação de produtos já existentes, retirando do artesanato a essência de seu valor: a originalidade e a unicidade das peças produzidas. De acordo com Souza (1993, p. 34), o valor dos produtos artesanais reside em características associadas à liberdade de criar inerentes às indústrias criativas (HARTLEY, 2005) e, portanto, inovar, retomando, continuando e transformando o saber que veio de uma tradição. Destituídos de tal valor, os produtos artesanais tornam-se tão somente artefatos, que precisam ter preço baixo para seduzir os compradores-revendedores como, por exemplo, no sistema produtivo tradicional têxtil em que $80 \%$ dos compradores dos estabelecimentos comerciais são lojistas e, portanto, vão adicionar ao preço de venda desses produtos, em seus estabelecimentos comerciais, o custo de aquisição, despesas administrativas, fiscais, tributárias e sua rentabilidade.

O não atendimento de uma demanda crescente está presente em dificuldades de mercado identificadas pela pesquisa, como produtos sem saída e baixa remuneração do trabalho. Problemas de demanda podem ser potencializados, por exemplo, como em Resende Costa, com o aumento do número de clientes turistas, que compram diretamente nas lojas da cidade. Essa mudança no perfil da demanda constitui uma oportunidade para o aumento da rentabilidade do sistema produtivo. Portanto, parece ser fundamental oferecer produtos de maior valor agregado, isto é, criativos, originais e inovadores, capazes de justificar um desembolso maior para a aquisição de peças. 
Dessa forma, a partir dos resultados apresentados, observa-se ser adequado e necessário restituir à produção nos SPTs seu caráter essencialmente artesanal. Talvez esse seja um caminho para assegurar, de forma sustentável, a viabilidade econômica territorial dos sistemas produtivos tradicionais analisados para, inclusive, atender às demandas por suvenires que reforma a imagem e as visitações em destinos turísticos regionais.

\section{CONSIDERAÇÕES FINAIS}

Este artigo investigou a construção de mercados e a gestão do desenvolvimento de produtos como suvenires em dois Sistemas Produtivos Tradicionais (SPTs) locais, associados às atividades turísticas regionais do Campo das Vertentes, a partir de SPTs tradicionais têxtil no município de Resende Costa, e os SPTs mineroartesanal, nos municípios de Catas Altas da Noruega, Mariana e Ouro Preto, ambos situados no estado de Minas Gerais - Brasil. Os dados observados nesses dois casos de SPTs analisados podem ser caracterizados como uma relação, fruto da interação da sociedade civil organizada e imersa, conforme Granovetter (2002), em laços fortes e fracos, que conformam as relações de confiança nesses destinos turísticos regionais.

A contribuição deste trabalho foi descrever as práticas existentes e como procedimentos da gestão do portfólio de produtos podem contribuir para a melhoria da vida dos envolvidos nesses SPTs que estão relacionados com as demandas e atividades de destinos turísticos. Sua contribuição adicional está em revelar que ao se analisar sistemas produtivos tradicionais pode-se evidenciar aspectos que inibem a inovação no desenvolvimento de produtos para atender a novas demandas do mercado. Neste estudo, foi observado que a divisão do trabalho e a especialização, presentes nesses sistemas, são aspectos que atuam, de modo não intencional, com anti-inovações (ABRAHAMSON, 1991) dos próprios sistemas produtivos tradicionais.

Todavia, a pesquisa realizada traz algumas limitações, como a impossibilidade de generalizar seus resultados e o fato de as informações sobre os revendedores e consumidores terem sido retiradas do discurso dos produtores e comerciantes pertencentes aos sistemas estudados (e não de entrevistas com os próprios revendedores e consumidores). Além disso, pelo fato de utilizar dados secundários, não foi possível efetuar comparações entre os dois sistemas relativamente a todas as características abordadas.

A despeito dessas limitações, os resultados apontam várias oportunidades para novas pesquisas. Em primeiro lugar, seria importante efetuar estudos em outros sistemas produtivos, denominados artesanato, da gestão do desenvolvimento de produtos. Em segundo lugar, parece ser de fundamental importância efetuar pesquisas com os revendedores para o aprofundamento analítico sobre a oferta de produtos dos dois sistemas aqui investigados, e com os consumidores finais para identificar os atributos valorizados nos produtos e os elementos da percepção de valor. Seria oportuno, também, aplicar aos portfólios dos sistemas estudados pelo menos um dos modelos descritos por Cooper, Edgett e Kleinschmidt (1997a).

Por fim, os resultados permitem propor algumas recomendações práticas. Em primeiro lugar, os resultados evidenciam que os SPTs estudados requerem a atuação do Estado, e algo que evidencia um recente avanço dessa atuação foi a criação da Lei n 13.180, de 22 de outubro de 2015, que normatiza as diretrizes para políticas públicas de fomento à profissão de artesão e autoriza o Poder Executivo, em seus diferentes entes governamentais, a apoiar os profissionais do artesanato (BRASIL, 2015) em seus SPTs e 
seus mercados, como os destinos turísticos com seus suvenires. Somado a isso, a atuação do Estado também pode ser por meio de parcerias com outros atores, como universidades, ONGs e organizações da iniciativa privada (especialmente as empresas que revendem os produtos desses sistemas), no desenvolvimento das potencialidades dos produtos em territórios criativos (EMMENDOERFER; ASHTON, 2014). Tudo indica que isso é possível e não implica na perda do conhecimento tácito local. Ao contrário, este deve ser preservado e até resgatado enquanto é tempo, não somente por razões de ordem cultural e histórica, como também para assegurar a rentabilidade e a sustentabilidade econômica dos sistemas produtivos tradicionais.

Nesse sentido, é necessário registrar os conhecimentos dos artesãos mais velhos, que são os únicos que detêm as habilidades legadas pela tradição. Esses conhecimentos precisam ser transmitidos às novas gerações, para que estas possam dar continuidade à produção tradicional e renová-la com suas ideias para poder continuar a atender às demandas nos destinos turísticos. Isso pressupõe conhecimento dos processos de produção, o que vai muito além da capacidade de realizar as tarefas isoladas que o compõem, ao mesmo tempo um processo de aprendizagem complementar para os estudantes e egressos formados em turismo e áreas afins.

Uma iniciativa interessante para apoiar e estimular o desenvolvimento de novos produtos seria a criação de parcerias com os departamentos de arte e design existentes em universidades públicas e privadas para que produtos interfuncionais sejam desenvolvidos em parceria com equipes multifuncionais (CLARK; WHEELWRIGHT, 1993). Já existem algumas experiências no Brasil e no exterior nesse sentido. Sem dúvida, porém, os conhecimentos oriundos da administração, especialmente das áreas de operações e marketing, são fundamentais para aprimorar a gestão do desenvolvimento de produtos dos sistemas estudados e assegurar sua sustentabilidade face a um mercado cada vez mais competitivo, onde mercadorias artesanais têm espaço, desde que mantenham o que as diferencia de mercadorias comuns: seu valor cultural e histórico, seu estilo, a originalidade e criatividade conferida pelos artesãos, como um tipo de ocupação laboral da classe criativa (FLORIDA, 2011) que as concebem.

\section{REFERÊNCIAS}

ABRAHAMSON, E. Managerial fads and fashions: the diffusion and rejection of innovations, Academy of Management Review, v. 16, n. 3, p. 586-612, 1991.

BOURDIEU, P. A economia das trocas simbólicas. 7. ed. São Paulo: Perspectiva, 2011.

BRASIL. Lei n. 13.180, de 22 de outubro de 2015. Dispõe sobre a profissão de artesão e dá outras providências. Brasília: Presidência da República, Casa Civil, Subchefia para Assuntos Jurídicos. Disponível em: <http://www.planalto.gov.br/ccivil_03/_Ato2015-2018/2015/ Lei/L13180.htm>. Acesso em: 29 dez. 2015.

BROWN, S. Marketing science in a postmodern world: introduction to the special issue. European Journal of Marketing, v. 31, n. 3-4, p. 167-182, 1997.

CLARK, K. B.; WHEELWRIGHT, S. C. Managing new product and process development. New York: The Free Press, 1993. 
COOPER, R. G. Winning at new products: accelerating the process from idea to launch. 2. ed. Reading: Addison-Wesley Publishing, 1993.

COOPER, R. G.; EDGETT S. J.; KLEINSCHMIDT, E. J. Portfolio management in new product development: lessons from the leaders - I. Research Technology Management, v. 40, n. 5, p. 16-28, 1997a.

COOPER, R. G.; EDGETT S. J.; KLEINSCHMIDT, E. J. Portfolio management in new product development: lessons from the leaders - II. Research Technology Management, v. 40, n. 6, p. 43-52, 1997b.

EMMENDOERFER, M. L.; ASHTON, M. S. Territórios criativos e suas relações com o turismo. Revista Turismo \& Desenvolvimento, v. 3, n. 21-22, p. 139-151, 2014. Disponível em: <https://www.ua.pt/ ReadObject.aspx?obj=34847>. Acesso em: 29 dez. 2015.

EMMENDOERFER, L. et al. A formação dos circuitos turísticos mineiros: uma política pública descentralizada e democratizante? Revista Acadêmica do Observatório de Inovação do Turismo, v. 2, n. 4, p. 1-18, 2007. Disponível em: <http://www.spell.org.br/documentos/download/26022>. Acesso em: 5 dez. 2015.

FLORIDA, R. A Ascensão da Classe Criativa: e seu papel na transformação do trabalho, lazer, comunidade e cotidiano. Porto Alegre, RS: L\&PM, 2011.

FREIRE-MEDEIROS, B.; CASTRO, C. A cidade e seus souvenirs: o Rio de Janeiro para o turista ter. Revista Brasileira de Pesquisa em Turismo, v. 1, n. 1, p. 34-53, 2007. Disponível em: <http://dx.doi. org/10.7784/rbtur.v1i1.78>. Acesso em: 29 dez. 2015.

FUNDAÇÃO CENTRO TECNOLÓGICO DE MINAS GERAIS. Levantamento das unidades de produção artesanal (UPAs) de pedra-sabão [Relatório]. Belo Horizonte: CETEC/MG, 2006.

GAVIRA, M. O. et al. Gestão da inovação tecnológica: uma análise da aplicação do funil de inovação em uma organização de bens de consumo. Revista de Administração Mackenzie, v. 8, n. 1, p. 77-107, 2007.

GORDON, B. The souvenir: messenger of the extraordinary. Journal of Popular Culture, v. 20, n. 3, p. 135-146, 1986.

GRANOVETTER, M. A Theoretical Agenda for Economic Sociology. In: GUILLEN, M. et al. (Eds.). The new economic sociology: developments in an emerging field. Russell Sage Foundation, 2002. p. 35-59.

GRIFFIN, A.; PAGE, A. PDMA success measurement project: recommended measures for product development success and failure. Journal of Product Development Innovation Management, v. 13, n. 6, p. 478-496, 1996.

HARTLEY, J. (Ed.). Creative industries. London: Blackwell Publishing, 2005.

HITCHCOCK, M.; TEAGUE, K. (Eds.). Souvenirs: The material culture of tourism. Aldershot: Ashgate, 2000.

HORODYSKI, G. S.; MANOSSO, F. C.; GÂNDARA, J. M. G. O consumo de souvenirs e a experiência turística em Curitiba (PR). Caderno Virtual de Turismo, v. 12, n. 3, p. 323-342, 2012. Disponível em: $<\mathrm{http} / /$ www.ivt.coppe.ufrj.br/caderno/index.php?journal=caderno\&page $=$ article\&op=view\&path $\% 5 \mathrm{~B}$ \%5D=693\&path\%5B\%5D=338>. Acesso em: 22 dez. 2015. 
HUNT, S. D.; LAMBE, C. J. Marketing's contribution to business strategy: relationship marketing and resource-advantage theory. International Journal of Management Reviews, v. 2, n. 1, p. 17-43, 2000.

KOTLER, P.; TRIAS DE BES, F. Marketing lateral: uma abordagem revolucionária para criar novas oportunidades em mercados saturados. Rio de Janeiro: Elsevier, 2004.

KOTLER, P.; KELLER, K. L. Administração de marketing. 12. ed. São Paulo: Prentice Hall, 2006.

LITTRELL, M. A.; ANDERSON, L. F.; BROWN, P. J. What makes a craft souvenir authentic? Annals of Tourism Research, v. 20, n. 1, p. 197-215, 1993.

MAZZA, A. C. A.; IPIRANGA, A. S. R.; FREITAS, A. A. F. O design, a arte e o artesanato deslocando o centro. In: ENCONTRO DE ESTUDOS ORGANIZACIONAIS, 4, 2006. Porto Alegre, RS, Brasil, Anais... Curitiba: ANPAD, 2006. CD.

MORGAN, N.; PRITCHARD, A. On souvenires and metonymy: narratives of memory, metaphor and materiality. Tourist Studies, v. 5, n. 1, p. 29-53, 2005.

MORRA, L.; FRIEDLANDER, A. C. Case study evaluations. Washington, DC: World Bank, 1999.

NARVER, J. C.; SLATER, S. F. The effect of a market orientation on business profitability. Journal of Marketing, v. 54, n. 1, p. 20-35, 1990.

ROCHA, A.; CHRISTENSEN, C. Marketing: teoria e prática no Brasil. São Paulo: Atlas, 1999.

SANTOS, M. C. L.; SILVA, G. M. Tear: artesanato de Resende Costa. São João del-Rei: Funrei, 1997.

SANTOS, M. C. L.; SILVA, G. M.; MORETTI, A. R. Artesanato: contando teares. São João del-Rei: Funrei, 1998.

SILVA, G. M. Mercados como construções sociais: divisão do trabalho, organização e estrutura social de um mercado em um território municipal. 2010. Tese (Doutorado em Sociologia) - Universidade Federal de Minas Gerais, Belo Horizonte, MG, Brasil, 2010. Disponível em: <http://www.bibliotecadigital.ufmg. $\mathrm{br} / \mathrm{dspace} / \mathrm{bitstream} /$ handle/1843/VCSA-874GMS/tesegms2010fafichufmg.pdf?sequence $=1>$. Acesso em: 02 jan. 2016.

SILVA, G. M.; ALMEIDA, M. R.; FERREIRA, R. V. Redes Interorganizacionais entre Fábricas de Souvenirs em Estanho no Destino Turístico de São João del-Rei e Tiradentes-MG. Turismo em Análise, v. 25, n. 3, p. 677-699, 2014. Disponível em: <DOI 10.11606/issn.1984-4867.v25i3p677-699>. Acesso em: 20 jun. 2017.

SILVA, G. M.; EMMENDOERFER, M. L.; NEVES, J. A. B. Artesanato: comércio e inovação na indústria de base artesanal. In: BENDASSOLLI, P. F. et al. (2009). Indústrias criativas no Brasil. São Paulo: Atlas, p. $169-178$.

SILVA, G. M.; TANNUS, M. B.; MOREIRA, C. V. R. Economia e sociedade no sistema de produção mineroartesanal. In: SIMPÓSIO DE ENGENHARIA DE PRODUÇÃO, 13, 2006. Bauru, SP, Anais eletrônicos... Bauru, SP. UNESP, 2006. Disponível em: <http://www.simpep.feb. unesp.br/anais/anais_13/ artigos/183.pdf>. Acesso em: 17 jan. 2016. 
SOARES, E. B. S.; EMMENDOERFER, M. L.; MONTEIRO, L. P. Gestão pública no turismo e o desenvolvimento de destinos turísticos em um estado da Federação Brasileira: uma análise do planejamento estratégico do turismo em Minas Gerais (2007-2010). TMStudies, Faro, v. 9, n. 2, p. 50-56, 2013. Disponível em: <http://www.scielo. mec.pt/scielo.php?script=sci_art text\&pid=S2182-84582013000200008\&lng=pt $\& n r m=i s o>$. Acesso em: 02 fev. 2015.

SOARES, R. M. F.; FISCHER, T. M. D. Aqui aprendeu da mãe que aprendeu da mãe: memórias e significados do artesanato no território do Sisal/Bahia. In: ENCONTRO NACIONAL DA ANPAD, 34, 2010. Rio de Janeiro, RJ, Brasil, Anais... Curitiba: ANPAD, 2006. CD.

SOUZA, T. Uma estratégia de marketing para cooperativas de artesanato: o caso do Rio Grande do Norte. Revista de Administração de Empresas, v. 33, n. 1, p. 30-38, 1993. Disponível em: <http://dx.doi. org/10.1590/S0034-75901993000100004>. Acesso em: 27 dez. 2015.

TAVARES, M. C.; PINTO, V. B. Novos produtos sob o enfoque do sistema de consumo e a orientação para o mercado. Gestão e Sociedade, v. 2, n. 3, 2008. Disponível em: <http://www.gestaoesociedade.org/ gestaoesociedade/article/view/542/521>. Acesso em: 5 jan. 2016. 